\title{
The effect of anakinra to nephrotoxicity with cisplatin induced in rats: Biochemical, gene expression and histopathological evaluation
}

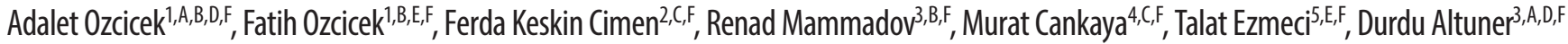 \\ 1 Department of Internal Medicine, Faculty of Medicine, Erzincan University, Turkey \\ ${ }^{2}$ Department of Pathology, Faculty of Medicine, Erzincan University, Turkey \\ ${ }^{3}$ Department of Pharmacology, Faculty of Medicine, Erzincan University, Turkey \\ ${ }^{4}$ Department of Biology, Arts and Sciences, Erzincan University, Turkey \\ ${ }^{5}$ Department of Public Health, Faculty of Medicine, Erzincan University, Turkey \\ A - research concept and design; $\mathrm{B}$ - collection and/or assembly of data; $\mathrm{C}$ - data analysis and interpretation; \\ $\mathrm{D}$ - writing the article; $\mathrm{E}$ - critical revision of the article; $\mathrm{F}$ - final approval of the article
}

Address for correspondence

Durdu Altuner

E-mail: durdualtuner@hotmail.com

Funding sources

None declared

Conflict of interest

None declared

Received on February 17, 2017

Reviewed on June 12,2017

Accepted on July 10, 2017

\begin{abstract}
Background. Oxidative stress and interleukin-1 beta (IL-1B) have been reported to play a role in the pathogenesis of nephrotoxicity induced by cisplatin.

Objectives. The objective of this study was to investigate the effect of anakinra, which is an IL-1B receptor antagonist, on cisplatin-induced nephrotoxicity in rats, through biochemical, gene expression and histopathological analyses.

Material and methods. The study was designed with 4 groups. For 1 week, the control group (C) and the cisplatin (Cis) group received distilled water, while the cisplatin + anakinra 50 (Cis + ANA50) group and the cisplatin + anakinra 100 (Cis + ANA100) group were intraperitoneally administered $50 \mathrm{mg} / \mathrm{kg}$ and $100 \mathrm{mg} / \mathrm{kg}$ of anakinra, respectively. The Cis, Cis + ANA50 and Cis + ANA100 groups were intraperitoneally injected with a $2.5 \mathrm{mg} / \mathrm{kg}$ dose of cisplatin for 7 days. After sacrifice, the kidney tissue of each rat was extracted for the assessment of the malondialdehyde (MDA) and total glutathione (tGSH) levels, and for gene expression analyses of $/ L-1 \beta$. The kidney tissues were histopathologically evaluated. Statistical analyses of the data were performed using one-way analysis of variance (ANOVA).

Results. The administration of cisplatin (the Cis group) yielded a higher level of MDA $(4.75 \pm 0.25 \mathrm{nmol} / \mathrm{mL}$; $p<0.001)$ and lower levels of tGSH $(1.80 \pm 0.35 \mathrm{mg} / \mathrm{L} ; \mathrm{p}<0.001)$ compared to other groups. Cisplatin also increased IL-1 $\beta$ gene expression $(6.33 \pm 0.27$ gene expression levels; $p<0.001)$ compared to other groups. The impact of anakinra on the MDA and TGSH levels, and on IL-1 $\beta$ gene expression induced by cisplatin was observed as a reversal of these findings $(p<0.05)$. Anakinra better prevented an increase of the levels of MDA and IL-1 1 at a dose of $100 \mathrm{mg} / \mathrm{kg}$ compared to a $50 \mathrm{mg} / \mathrm{kg}$ dose.
\end{abstract}

Conclusions. Anakinra prevents oxidative kidney damage induced by cisplatin in a dose-dependent manner. This result suggests that anakinra may be useful in the treatment of cisplatin-induced kidney damage.

Key words: rats, cisplatin-nephrotoxicity, anakinra

DOI

10.17219/acem/75775

Copyright

Copyright by Author(s)

This is an article distributed under the terms of the

Creative Commons Attribution Non-Commercial License

(http://creativecommons.org/licenses/by-nc-nd/4.0/) 


\section{Introduction}

Cisplatin is a platinum-derived anticancer drug which is widely used in chemotherapy. Since cisplatin is a noncell-cycle specific chemotherapeutic agent, it is a broadspectrum drug, commonly used in the treatment of various solid cancer types (stomach, testicular, ovarian, bladder, kidney, uterocervical, head and neck). ${ }^{1}$ However, nephrotoxicity during cisplatin chemotherapy makes it necessary to use cisplatin in limited doses, and sometimes even to discontinue the treatment. ${ }^{2}$ While the administration of cisplatin at low doses causes necrosis in the tubule cells of the kidney, high doses lead to apoptosis. ${ }^{3}$ Cisplatin has been reported to cause severe damage, especially in the epithelial cells of the proximal tubule of the kidney. ${ }^{4}$ Free oxygen radicals have been demonstrated to play a role in cellular death due to the use of cisplatin. ${ }^{5}$ On the other hand, interleukin- 1 beta (IL-1 $\beta$ ) has been reported to play a crucial role in the pathogenesis of nephrotoxicity induced by cisplatin. ${ }^{6}$ These results suggest that antioxidants and IL-1 $\beta$ antagonists may be beneficial in the prevention of cisplatin nephrotoxicity. Anakinra, which we tested against cisplatin nephrotoxicity in the present study, is a recombinant human IL-1 $\beta$ receptor antagonist and the first biological agent which has been demonstrated to block pro-inflammatory effects in patients with rheumatoid arthritis. ${ }^{7}$ Hasturk et al. reported on the antioxidant activity of anakinra in animals. ${ }^{8}$ There are studies which associate the protective effect of anakinra with antioxidant activity resulting from the blockage of IL- $\beta$ receptors. ${ }^{9}$ Anakinra has also been reported to protect the ovarian tissue from ischemia-reperfusion injury by anti-inflammatory and antioxidant activity. ${ }^{10}$ It was found that anakinra suppressed hyperalgesia by preventing an increase in the malondialdehyde (MDA), myeloperoxidase and IL-1 $\beta$ levels, and a decrease in the total glutathione (tGSH) levels. ${ }^{11}$ In the literature, there have been no studies on the use of anakinra, taking into consideration both its antioxidant and IL-1 $\beta$-antagonist properties against cisplatin nephrotoxicity. Therefore, the objective of this study was to investigate the effect of anakinra against cisplatininduced nephrotoxicity in rats, through biochemical, gene expression and histopathological analyses.

\section{Material and methods}

\section{Animals}

A total of 40 male albino Wistar rats, each weighing 220$230 \mathrm{~g}$, were randomly chosen. Prior to the experiment, the rats were divided into 4 groups, with 10 rats per group. The rats were kept and fed in the pharmacology laboratory at normal room temperature $\left(22^{\circ} \mathrm{C}\right)$. The animal experiments were performed in accordance with the National Guidelines for the Use and Care of Laboratory Animals, and approved by the local animal ethics committee (No. 179, November 27, 2015).

\section{Chemical substances}

Cisplatin, ketamine hydrochloride and anakinra were purchased from Koçak Farma Drug Industry (Istanbul, Turkey), Pfizer Drugs, Ltd. (Istanbul, Turkey) and Swedish Orphan Biovitrum AB (Stockholm, Sweden), respectively.

\section{Experimental groups}

The experimental animals were divided into control (C), cisplatin (Cis), cisplatin + anakinra 50 (Cis + ANA50), and cisplatin + anakinra 100 (Cis + ANA100) groups.

\section{Experimental procedure}

The Cis + ANA50 and Cis + ANA100 groups were intraperitoneally administered $50 \mathrm{mg} / \mathrm{kg}$ and $100 \mathrm{mg} / \mathrm{kg}$ of anakinra, respectively. As in the previous studies, anakinra was given intraperitoneally. In addition, the effects of anakinra on antioxidants and cytokines had been investigated previously at these dosages..$^{10}$ Distilled water was given to the $\mathrm{Cis}$ and $\mathrm{C}$ groups as a solvent in the same way. Since anakinra is a solution dissolved in distilled water, we also used distilled water as a solvent. One hour after anakinra was administered, the Cis, Cis + ANA50 and Cis + ANA100 groups were injected with a $2.5 \mathrm{mg} / \mathrm{kg}$ dose of cisplatin intraperitoneally. In the literature, drugs that have been investigated for protective effects against cisplatin toxicity are generally given to experimental animals $1 \mathrm{~h}$ before cisplatin. ${ }^{12}$ In our preliminary study, administering cisplatin at a dose of $2.5 \mathrm{mg} / \mathrm{kg}$ for 1 week resulted in significant nephrotoxicity in the animals. These procedures were repeated once a day for 7 days. At the end of this period, all the rats were sacrificed with high-dose ketamine hydrochloride anesthesia and their kidney tissues were removed. Following the macroscopic evaluation of the kidney tissues, the MDA, tGSH and $I L-1 \beta$ gene expression levels were determined. In addition, the kidney tissues were histopathologically evaluated. The results obtained from the Cis + ANA50, Cis + ANA100 and C groups were evaluated in comparison with the Cis group.

\section{Biochemical analysis}

\section{Malondialdehyde analysis}

According to the method defined by Ohkawa et al., MDA forms a pink complex with thiobarbituric acid (TBA) at $95^{\circ} \mathrm{C}$, which can be measured using spectrophotometry at a wavelength of $532 \mathrm{~nm} .{ }^{13}$ A sample of $25 \mathrm{mg}$ of tissue was homogenized using a solution of $1.15 \% \mathrm{KCl}$. Homogenates were centrifuged at $5000 \mathrm{~g}$ for $20 \mathrm{~min}$, and the supernatants were used to determine the amount of MDA; $250 \mu \mathrm{L}$ of homogenate, $100 \mu \mathrm{L}$ of $8 \%$ sodium dodecyl sulfate (SDS), $750 \mu \mathrm{L}$ of $20 \%$ acetic acid, $750 \mu \mathrm{L}$ of $0.08 \% \mathrm{TBA}$, and $150 \mu \mathrm{L}$ of purified water were pipetted into capped test tubes and 
vortexed. The mixture was left for incubation at $100^{\circ} \mathrm{C}$ for $60 \mathrm{~min}$ before $2.5 \mathrm{~mL}$ of $\mathrm{n}$-butanol was added to it, and then spectrophotometric measurement was conducted. The amounts of red color formed were read at $532 \mathrm{~nm}$, using cuvettes of $3 \mathrm{~mL}$, and, taking into account dilution coefficients, the MDA amounts in the samples were determined, using the standard chart. The standard chart created using MDA stock solution was prepared before.

\section{Total glutathione analysis}

The amount of GSH in the total homogenate was measured according to the method of Sedlak and Lindsay with some modifications. ${ }^{14}$ The sample was weighed and homogenized in $2 \mathrm{~mL}$ of $50 \mathrm{mmol} / \mathrm{L}$ Tris- $\mathrm{HCl}$ buffer, containing $20 \mathrm{mmol} / \mathrm{L}$ of ethylenediaminetetraacetic acid (EDTA) and $0.2 \mathrm{mmol} / \mathrm{L}$ of sucrose at $\mathrm{pH} 7.5$. The homogenate was immediately precipitated with $0.1 \mathrm{~mL}$ of $25 \%$ trichloroacetic acid (TCAA), the precipitate was removed after centrifugation at $4200 \mathrm{rpm}$ for $40 \mathrm{~min}$ at $4^{\circ} \mathrm{C}$, and the supernatant was used to determine the GSH level. A total of $1500 \mu \mathrm{L}$ of measurement buffer $(200 \mathrm{mmol} / \mathrm{L}$ of Tris- $\mathrm{HCl}$ buffer, containing $0.2 \mathrm{mmol} / \mathrm{L}$ of EDTA at $\mathrm{pH}$ 7.5), $500 \mu \mathrm{L}$ of the supernatant, $100 \mu \mathrm{L}$ of $5,5^{\prime}$-Dithiobis (2-nitrobenzoic acid) (DTNB), and $7900 \mu \mathrm{L}$ of methanol were added to a tube and vortexed, and incubated for $30 \mathrm{~min}$ at $37^{\circ} \mathrm{C}$. DTNB was used as a chromogen and it formed a yellow-colored complex with sulfhydryl groups. The absorbance was measured at $412 \mathrm{~nm}$, using a spectrophotometer (Beckman DU 500; Beckman Coulter, Inc., Brea, USA). The standard curve was obtained by using reduced glutathione.

\section{Superoxide dismutase analysis}

The superoxide dismutase (SOD) activity was based on the generation of superoxide radicals, produced by xanthine and xanthine oxidase, which reacts with nitro blue tetrazolium to form formazan dye. The SOD activity was then measured at $560 \mathrm{~nm}$ by the degree of inhibition of this reaction. ${ }^{15}$

\section{Interleukin-1 beta quantity measurement}

The tissue homogenate IL-1 $\beta$ concentrations were measured using a rat-specific sandwich enzyme-linked immunosorbent assay Rat Interleukin-1 $\beta$ ELISA Kit (Cat. No. YHB0616Ra; Shanghai LZ Biotech Co., Ltd., Shanghai, China). The analyses were performed according to the manufacturers' instructions. Briefly, a monoclonal antibody specific for rat IL-1 $\beta$ was coated onto the wells of microplates. The tissue homogenate, standard solutions, biotinylated spesific monoclonal antibody and streptavidin-HRP were pipetted into these wells, and then incubated at $37^{\circ} \mathrm{C}$ for $60 \mathrm{~min}$. After washing, chromogen reagent $A$ and chromogen reagent $B$ were added, which were acted upon by the bound enzyme to produce a color. The mixture was incubated at $37^{\circ} \mathrm{C}$ for $10 \mathrm{~min}$. Then, a stop solution was added. The intensity of this colored product was directly proportional to the concentration of rat IL-1 $\beta$ present in the original specimen. At the end of the course, the well plates were read at $450 \mathrm{~nm}$ via a microplate reader (BioTek, Winooski, USA). The absorbance of the samples was estimated with formulas that used standard graphics.

\section{Gene expression of $I L-1 \beta$}

\section{RNA isolation}

RNA was isolated from the homogenized kidney tissue samples using a Roche Magna Pure Compact LC device with a MagNA Pure LC RNA Kit (Roche Diagnostics GmbH, Mannheim, Germany). The quantity and quality of the isolated RNA was assessed with a nucleic acid measurement device (MaestroNano; Nucleotest Bio Ltd., Budapest, Hungary). The $50 \mu \mathrm{L}$ RNA samples were stored at $-80^{\circ} \mathrm{C}$.

\section{Complementary DNA synthesis}

Complementary DNA (cDNA) was synthesized from the isolated RNA samples using a Transcriptor First Strand cDNA Synthesis Kit (Roche Diagnostics $\mathrm{GmbH}$ ). For each subject, $1 \mu \mathrm{L}$ of $\mathrm{dd}_{2} \mathrm{O}, 10 \mu \mathrm{L}$ of RNA and $2 \mu \mathrm{L}$ of random primer were combined and incubated in a thermal cycler for $10 \mathrm{~min}$ at $65^{\circ} \mathrm{C}$. After incubation, $4 \mu \mathrm{L}$ of reaction buffer, $0.5 \mu \mathrm{L}$ of RNAase, $2 \mu \mathrm{L}$ of deoxynucleotide mix, and $0.5 \mu \mathrm{L}$ of reverse transcriptase were added. The reactions were incubated for $10 \mathrm{~min}$ at $25^{\circ} \mathrm{C}$, for $30 \mathrm{~min}$ at $55^{\circ} \mathrm{C}$, for $5 \mathrm{~min}$ at $85^{\circ} \mathrm{C}$, and then they were held at $4^{\circ} \mathrm{C}$. At the end of incubation, $1 \mu \mathrm{L}$ of $\mathrm{RNase} \mathrm{H}$ was added. The reaction was stopped by allowing the polymerase chain rection (PCR) device to stand for $20 \mathrm{~min}$ at $37^{\circ} \mathrm{C}$. The prepared product was stored at $-80^{\circ} \mathrm{C}$.

\section{Quantitative gene expression evaluation} with real-time polymerase chain reaction

For each cDNA sample, the gene expression of $I L-1 \beta$ and the reference gene $(G 6 P D)$ was analyzed, using a Roche LightCycler 480 II Real-Time PCR instrument (Roche Diagnostics $\mathrm{GmbH}$ ). The PCR reactions were recorded in a final volume of $20 \mu \mathrm{L}$, including $5 \mu \mathrm{L}$ of cDNA, $3 \mu \mathrm{L}$ of distilled water, $10 \mu \mathrm{L}$ of LightCycler 480 Probes Master (Roche Diagnostics $\mathrm{GmbH}$ ), and $2 \mu \mathrm{L}$ of primer-probe set (Real-Time Ready single assay; Roche Diagnostics $\mathrm{GmbH}$ ). The cycle conditions of the relative quantitative PCR (qPCR) were preincubation at $95^{\circ} \mathrm{C}$ for $10 \mathrm{~min}$, followed by 45 amplification cycles of $95^{\circ} \mathrm{C}$ for $10 \mathrm{~s}$, at $6^{\circ} \mathrm{C}$ for $30 \mathrm{~s}$ and at $72^{\circ} \mathrm{C}$ for $1 \mathrm{~s}$, followed by cooling at $40^{\circ} \mathrm{C}$ for $30 \mathrm{~s}$. The qPCR analysis and the calculation of quantification cycle $(\mathrm{Cq})$ values for relative quantification were performed with the LightCycler 480 Software, v. 1.5 (Roche 
Diagnostics $\mathrm{GmbH}$ ). Relative quantitative amounts were calculated by dividing the target genes by the expression level of the reference gene. The reference gene was used for the normalization of the target gene expression.

\section{Histopathological examination}

The renal tissues taken from the rats were fixed in $10 \%$ formalin for $24 \mathrm{~h}$. Following the routine processing of tissue-embedded paraffin sections, $4 \mu \mathrm{m}$ slices were obtained from the paraffin blocks. After deparaffinization and rehydration, the slices were stained with hematoxylin and eosin (H\&E). The stained slices were evaluated under a light microscope (Olympus BX 52; Olympus, Tokyo, Japan) by a pathologist who did not know the applied treatment protocol. To assess inflammation and histopathological damage, some symptoms were examined, such as glomerular and tubular necrosis, dilatation and congestion in the blood vessels, and edema and hemorrhage in the interstitial area.

\section{Statistical analysis}

Statistical analyses were performed using the Statistical Package for Social Sciences, Windows v. 19.0 (SPSS Inc., Chicago, USA). Descriptive statistics for each variable were determined. The normality of data distribution was assessed by the Kolmogorov-Smirnov test. The results for continuous variables were demonstrated as mean \pm standard error of the mean (mean \pm SEM). The significance of differences between the groups was determined using the one-way analysis of variance (ANOVA) test followed by Tukey's analysis. The results obtained from the drug-treated groups were evaluated in comparison with the $\mathrm{Cis}$ and $\mathrm{C}$ groups. A p-value $<0.05$ was considered significant.

\section{Results}

\section{Biochemical results}

The MDA level was significantly higher $(\mathrm{p}<0.001)$ in the Cis group $(4.75 \pm 0.25 \mathrm{nmol} / \mathrm{mL})$ than that of the $\mathrm{Cis}+$ ANA50, Cis + ANA100 and C groups $(2.93 \pm 0.08 \mathrm{nmol} / \mathrm{mL}$, $1.93 \pm 0.14 \mathrm{nmol} / \mathrm{mL}$ and $2.03 \pm 0.39 \mathrm{nmol} / \mathrm{mL}$, respectively). As seen in Fig. 1, the amount of MDA was significantly higher in the kidney tissue of the Cis group rats than in the $C$ group ( $\mathrm{p}<0.001$ ). The level of MDA was significantly lower in the kidney tissue of the Cis + ANA50 and $\mathrm{Cis}+\mathrm{ANA} 100$ groups compared to the Cis group $(\mathrm{p}<0.001)$. There was a significant difference in the MDA levels between the Cis + ANA50 and C groups ( $<<0.01)$, while the levels of MDA were almost the same between the Cis + ANA100 and C groups ( $p>0.05)$.

The tGSH level in the Cis group $(1.80 \pm 0.14 \mathrm{mg} / \mathrm{L})$ was significantly lower than that of the Cis + ANA50, Cis + ANA100 and C groups $(3.15 \pm 0.18 \mathrm{mg} / \mathrm{L} ; \mathrm{p}<0.005$,
$5.03 \pm 0.29 \mathrm{mg} / \mathrm{L} ; \mathrm{p}<0.001$ and $5.47 \pm 0.27 \mathrm{mg} / \mathrm{L} ; \mathrm{p}<0.001$, respectively). The level of $\mathrm{tGSH}$ was significantly higher in the kidney tissue of the Cis + ANA50 and Cis + ANA100 groups than in the Cis group $(\mathrm{p}<0.001)$. There was a significant difference between the tGSH levels in the Cis + ANA50 and $\mathrm{C}$ groups, while the levels of tGSH were almost the same between the Cis + ANA100 and C groups (Fig. 2).

The SOD activity measured in the kidney tissue of the Cis group rats was $8.57 \pm 0.26 \mathrm{U} / \mathrm{g}$ protein, and the SOD activity in the Cis + ANA50, Cis + ANA100 and C groups were $5.55 \pm 0.34 \mathrm{U} / g$ protein, $3.8 \pm 0.3 \mathrm{U} / g$ protein and $3.4 \pm 0.22 \mathrm{U} / \mathrm{g}$ protein, respectively (Fig. 3).

The quantity of IL-1 $\beta$ was measured as $5.3 \pm 0.19 \mathrm{pg} / \mathrm{mL}$ in the kidney tissue of the Cis group. However, the amount of IL- $1 \beta$ was calculated as $3.1 \pm 0.16 \mathrm{pg} / \mathrm{mL}, 1.9 \pm 0.09 \mathrm{pg} / \mathrm{mL}$ and $1.6 \pm 0.13 \mathrm{pg} / \mathrm{mL}$ in the Cis + ANA50, Cis + ANA100 and $\mathrm{C}$ groups, respectively (Fig. 4).

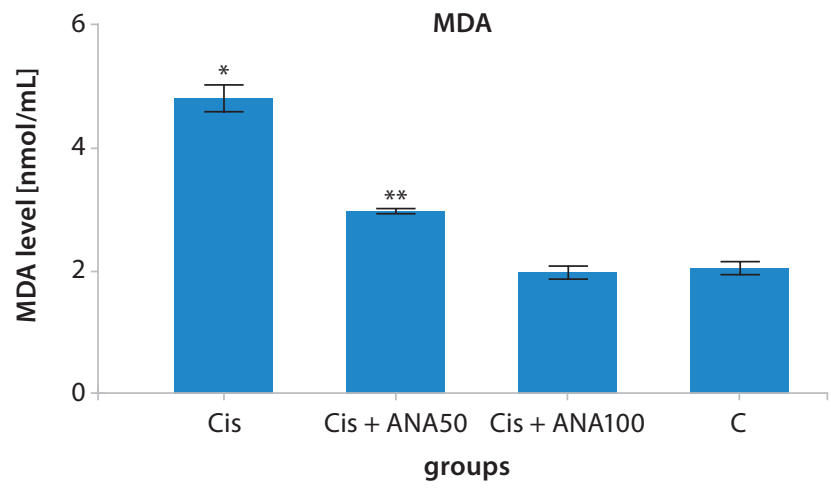

Fig. 1. The MDA levels in the study groups

MDA - malondialdehyde; Cis - group receiving cisplatin only; Cis + ANA50 - group receiving cisplatin and $50 \mathrm{mg} / \mathrm{kg}$ of anakinra; Cis + ANA100 - group receiving cisplatin and $100 \mathrm{mg} / \mathrm{kg}$ of anakinra; $C$ - control group, receiving no drugs; * $\mathrm{p}<0.001$ compared with the $C$ group; ${ }^{* *} p<0.01$ compared with the $C$ group.

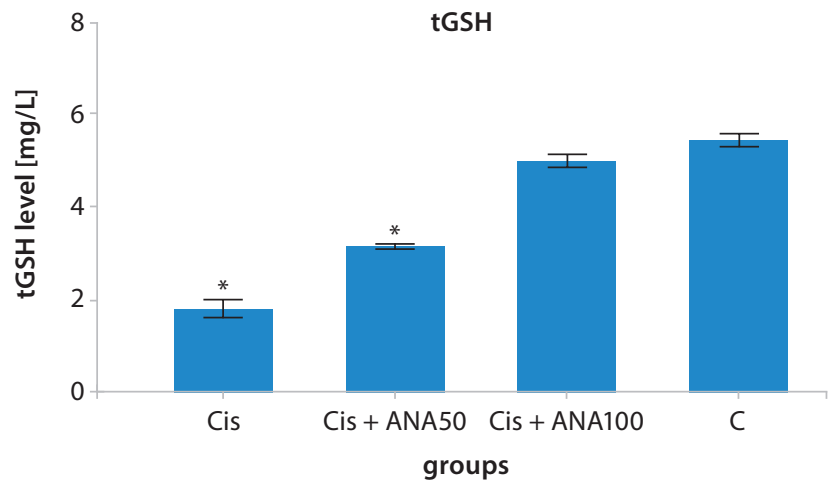

Fig. 2. The tGSH levels in the study groups

tGSH - total glutathione; Cis - group receiving cisplatin only; Cis + ANA50 - group receiving cisplatin and $50 \mathrm{mg} / \mathrm{kg}$ of anakinra; $\mathrm{Cis}+$ ANA100 - group receiving cisplatin and $100 \mathrm{mg} / \mathrm{kg}$ of anakinra; $\mathrm{C}$ - control group, receiving no drugs; ${ }^{*} \mathrm{p}<0.001$ compared with the $\mathrm{C}$ group. 


\section{Interleukin-1 beta gene expression results}

The $I L-1 \beta$ gene expression level was significantly higher ( $\mathrm{p}<0.001)$ in the Cis group $(6.33 \pm 0.27)$ than in the Cis + ANA50, Cis + ANA100 and C groups (3.63 \pm 0.20 , $2.62 \pm 0.18$, and $2.22 \pm 0.21$, respectively). As seen in Fig. 5, the gene expression level of $I L-1 \beta$ was significantly higher in the kidney tissue of the Cis group rats compared to other groups $(\mathrm{p}<0.001)$. There was no statistically significant difference between the Cis + ANA100 and C groups regarding the $I L-1 \beta$ gene expression levels ( $\mathrm{p}>0.05$ ).

\section{Histopathological results}

Histopathological examination of the renal tissue of the $C$ group showed normal glomerular structure, Bowman's capsule and Bowman's space (Fig. 6A). However, a wide hemorrhagic area, dilated and congested blood vessels, and interstitial inflammation were observed in the Cis group (Fig. 6B). Moreover, in the renal tissue of the Cis group, hemorrhage was accompanied by glomerular and tubular damage, edema (circle arrow), and interstitial hemorrhage areas (Fig. 6C). Tubular necrosis, interstitial infiltration, and dilated and congested blood vessels were observed in the renal tissue of the Cis group (Fig. 6D). A near-normal appearance, mildly persistent tubule irregularities, and hemorrhage were found in the kidney glomeruli of the Cis + ANA50 group rats (Fig. 6E), whereas protected near-normal glomerulus, proximal and distal tubules were observed in the renal tissue of the group administered $100 \mathrm{mg} / \mathrm{kg}$ of anakinra (Fig. 6F).

\section{Discussion}

In this study, the effect of anakinra on cisplatin-induced nephrotoxicity in rats was investigated through biochemical and histopathological findings, and through gene expression analysis. Cisplatin increased the levels of MDA and IL-1 $\beta$, and decreased the levels of tGSH in the renal tissue of rats. Anakinra prevented an increase of MDA and IL-1 $\beta$, and a decrease of tGSH due to cisplatin. Additionally, the histopathological examination of anakinra used at a dosage of $100 \mathrm{mg} / \mathrm{kg}$ was found to improve renal damage which occurred due to cisplatin.

The pathogenesis of the nephrotoxic effect of cisplatin has not been fully elucidated; however, it has been argued in previous studies that the increase in the production of reactive oxygen species (ROS) leads to nephrotoxicity. ${ }^{16}$ As is known, ROS play a key role in the pathogenesis of cellular damage. As it is understood from the results of our biochemical experiment, the amount of MDA was increased and the amount of tGSH was decreased in the renal tissue of the rats administered cisplatin. It has also been reported that cisplatin causes oxidative damage to the kidneys by increasing the amount of MDA. ${ }^{17}$ The increase in the MDA level, the end product of lipid peroxidation

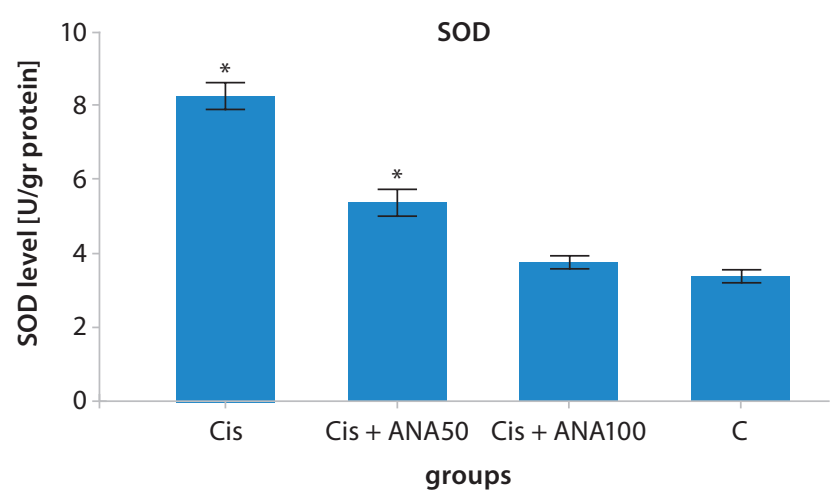

Fig. 3. The SOD levels in the study groups

SOD - superoxide dismutase; Cis - group receiving cisplatin only; Cis + ANA50 - group receiving cisplatin and $50 \mathrm{mg} / \mathrm{kg}$ of anakinra; Cis + ANA100 - group receiving cisplatin and $100 \mathrm{mg} / \mathrm{kg}$ of anakinra; $C$ - control group, receiving no drugs; ${ }^{*} p<0.001$ compared with the $\mathrm{C}$ group.

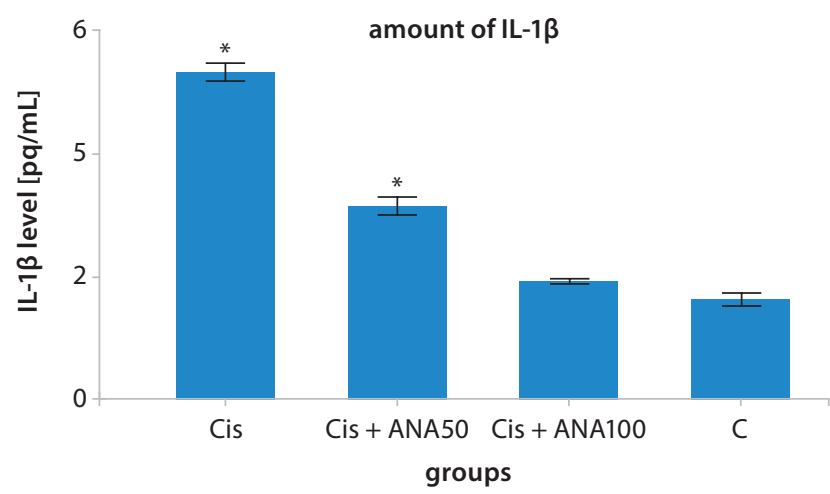

Fig. 4. The IL-1 $\beta$ levels in the study groups

IL-1 $\beta$ - interleukin-1 $\beta$; Cis - group receiving cisplatin only;

Cis + ANA50 - group receiving cisplatin and $50 \mathrm{mg} / \mathrm{kg}$ of anakinra;

Cis + ANA100 - group receiving cisplatin and $100 \mathrm{mg} / \mathrm{kg}$ of anakinra;

$C$ - control group, receiving no drugs; ${ }^{*} p<0.001$ compared with the $C$ group.

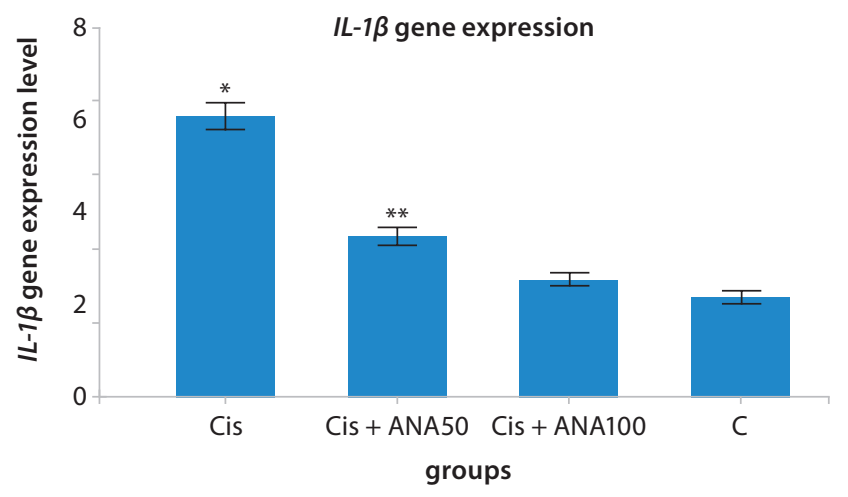

Fig. 5. The $I L-1 \beta$ gene expression levels in the study groups

IL-1 $\beta$ - interleukin-1 $\beta$; Cis - group receiving cisplatin only; Cis + ANA50 group receiving cisplatin and $50 \mathrm{mg} / \mathrm{kg}$ of anakinra; Cis + ANA100 - group receiving cisplatin and $100 \mathrm{mg} / \mathrm{kg}$ of anakinra; $\mathrm{C}$ - control group, receiving no drugs; ${ }^{*} p<0.001$ compared with the C group; ${ }^{* *} p<0.005$ compared with the $C$ group. 


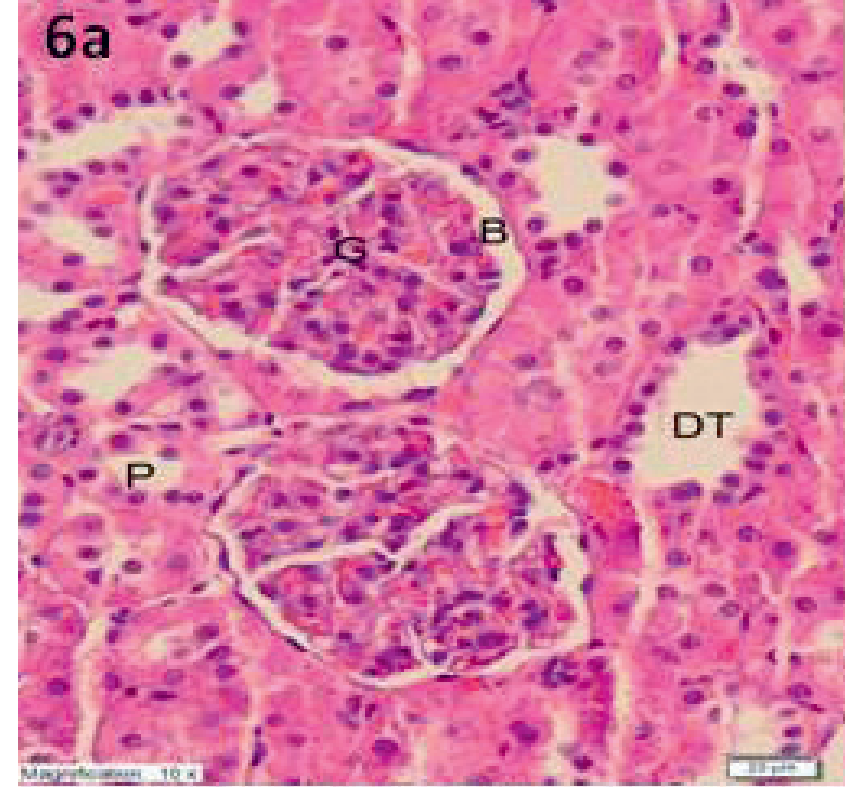

Fig. 6A. A section showing normal glomerular structure, Bowman's capsule and space, and proximal and distal tubules in the renal tissue of the control group $(H \& E, \times 200$ magnification)

G-glomerulus; B - Bowman's capsule; P - proximal tubule; D - distal tubules; H\&E - hematoxylin and eosin staining.

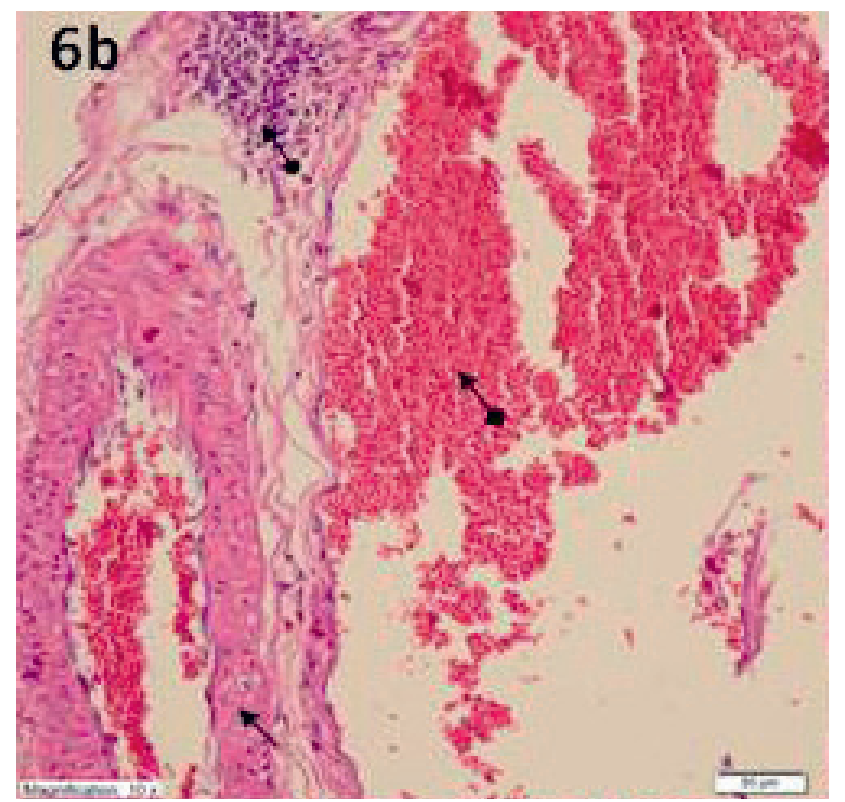

Fig. 6B. A section involving a wide hemorrhage area (square arrow), a dilated, congested blood vessel (straight arrow) and interstitial inflammation in the Cis group (H\&E, ×200 magnification)

Cis - group receiving cisplatin only;

H\&E - hematoxylin and eosin staining.

in the tissues, is indicative of the increased ROS. ${ }^{18}$ It has also been documented that oxidative stress and inflammation are important factors in the development of cisplatin-induced nephrotoxicity. ${ }^{19}$ In our study, significant increases in the amount of MDA, as well as in the proinflammatory $I L-1 \beta$ gene expression and amounts, were noted in the kidneys of animals receiving cisplatin.

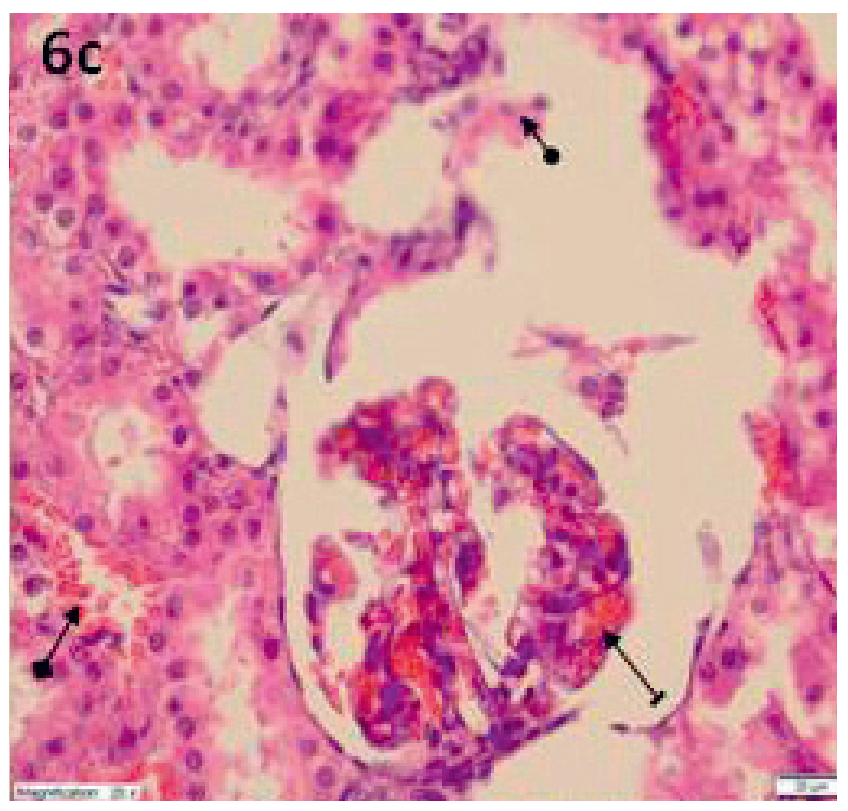

Fig. 6C. A section showing hemorrhage accompanied by glomerular damage (line arrow), diffuse tubular damage, edema (circle arrow), and an interstitial hemorrhage area (square arrow) in the Cis group (H\&E, $\times 400$ magnification)

Cis - group receiving cisplatin only;

H\&E - hematoxylin and eosin staining.

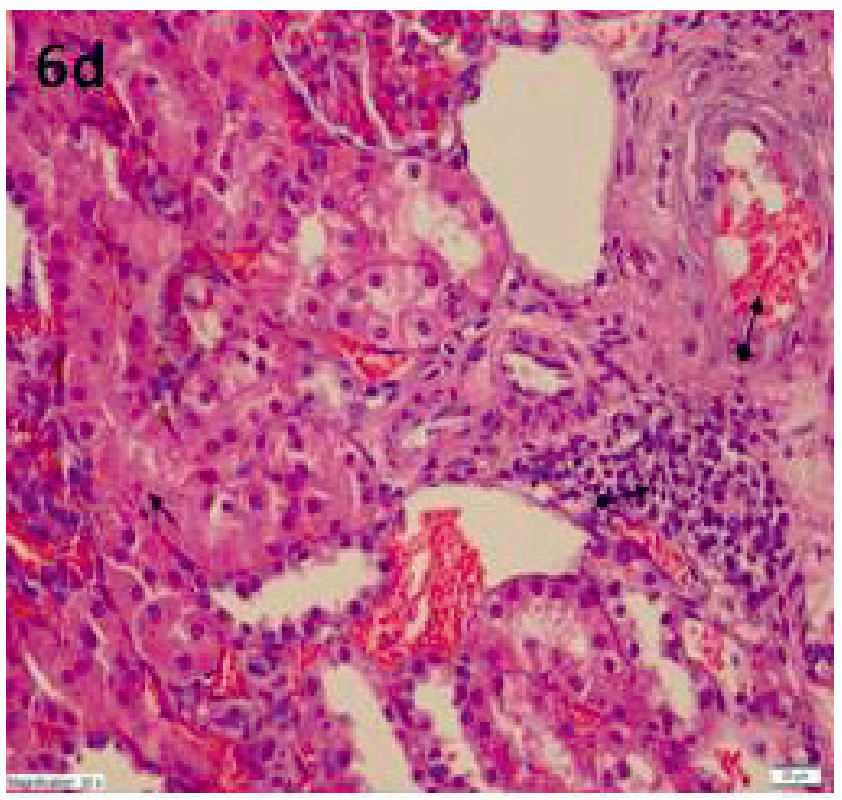

Fig. 6D. A section involving tubular necrosis (straight arrow), interstitial infiltration (circle arrow) and dilated, congested blood vessels (square arrow) in the renal tissue of the Cis group (H\&E, $\times 400$ magnification)

Cis - group receiving cisplatin only;

H\&E - hematoxylin and eosin staining.

Interleukin-1 beta has a number of functions, including the oxidative burst of neutrophils via the signaling molecules of inflammation and the release of free radicals. ${ }^{20}$ The increased expression and amount of IL-1 $\beta$ we found supports the direct association between IL-1 $\beta$ and oxidative stress in the renal tissue with high MDA and low tGSH and SOD levels. Additionally, it has been stated 


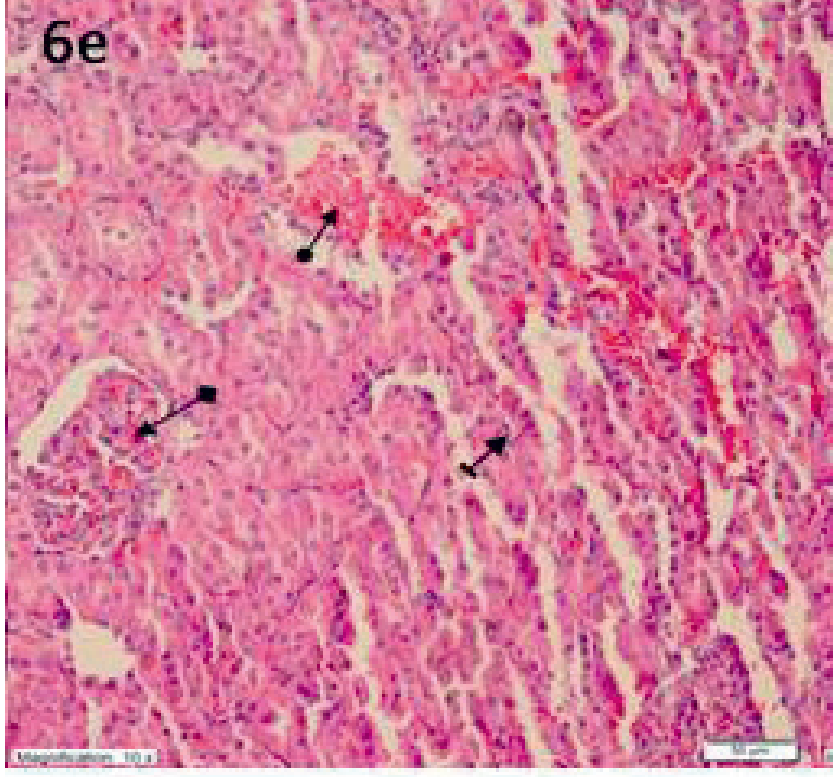

Fig. 6E. A section involving a near-normal appearance (square arrow), mildly persistent tubular irregularities (line arrow) and hemorrhage areas (circle arrow) in the kidney glomeruli of the Cis + ANA50 group (H\&E, ×200 magnification)

Cis + ANA50 - group receiving cisplatin and $50 \mathrm{mg} / \mathrm{kg}$ of anakinra; H\&E - hematoxylin and eosin staining.

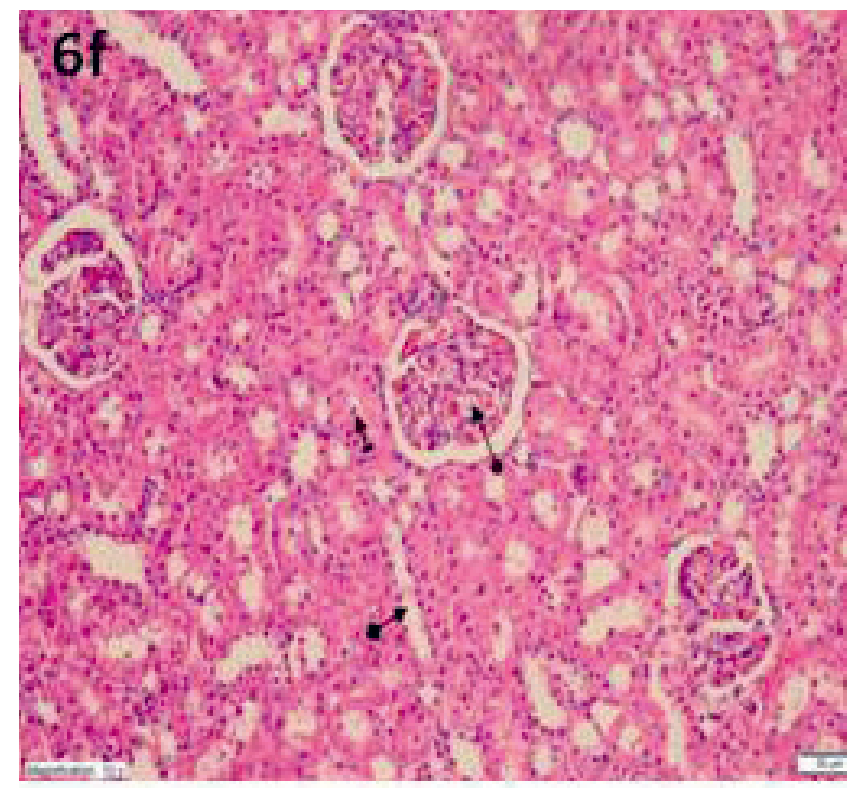

Fig. 6F. A section showing a near-normal glomerulus (circle arrow), proximal tubule (line arrow), and distal tubule (square arrow) in the renal tissue of the $\mathrm{Cis}+\mathrm{ANA100}$ group $(\mathrm{H} \& \mathrm{E}, \times 200$ magnification)

Cis + ANA100 - group receiving cisplatin and 100 mg/kg of anakinra; H\&E - hematoxylin and eosin staining.

with histopathological examinations that cisplatin leads to renal damage by increasing the levels of oxidants and of IL-1 $\beta$. Cisplatin is known to cause interstitial inflammation, dilated and congested blood vessels, hemorrhage, and edema in the kidneys. ${ }^{21-23}$ Furthermore, it has been argued that the serious side effects of cisplatin, such as tubular necrosis, are caused by the induction of cytokine production. ${ }^{24}$ In our experimental results, we also found that there was evidence of inflammatory markers (hemorrhage, dilated and congested blood vessels, interstitial inflammation, and edema), glomerular damage and tubular necrosis in the kidney tissues of the cisplatin group, whose MDA and IL-1 $\beta$ gene expression levels increased significantly. These biochemical and histopathological findings suggest that oxidative stress develops in the kidney tissue when we administer cisplatin.

There are endogenous antioxidant defense systems against ROS in living tissues. However, an overproduction of ROS leads to the consumption of the antioxidant defense system and also to oxidative stress. ${ }^{25}$ In our current study, the levels of non-enzymatic and enzymatic antioxidants, such as tGSH and SOD, in the kidney tissue of the cisplatin group (in which the above-mentioned histopathological damage was observed) was decreased. There are studies showing that a significant reduction in the amount of tGSH is associated with oxidative stress in cisplatin nephrotoxicity. ${ }^{26}$ It has also been reported that the SOD activity decreases in the kidney tissue with tubular damage, apoptosis and inflammation due to cisplatin treatment. ${ }^{27}$ These results support the hypothesis that cisplatin nephrotoxicity is associated with oxidative stress.

This information has led to the testing of anti-inflammatory and antioxidant drugs against cisplatin nephrotoxicity. The IL-1 $\beta$ receptor antagonist anakinra, which is used against the nephrotoxicity of cisplatin, has been found to prevent the increase in MDA and IL-1 $\beta$, caused by cisplatin, and also to decrease the tGSH and SOD levels in the kidney tissue. The antioxidant and anti-inflammatory features of anakinra are believed to protect the renal tissue against the oxidative damage of cisplatin., ${ }^{7,8}$ In addition, there are studies associating the protective effect of anakinra with the antioxidant activity resulting from the blockage of IL- $\beta$ receptors. ${ }^{9}$ Severe pathological findings were observed in the renal tissue of the Cis group with significantly increased levels of oxidants and IL-1 $\beta$, such as wide hemorrhage areas, dilated and congested blood vessels, interstitial inflammation, glomerular and tubular damage, edema, and tubular necrosis. However, while mildly persistent tubule irregularities and hemorrhage were seen in the Cis + ANA50 group with high amounts of tGSH identified, the glomerulus, proximal tubule and distal tubule were evaluated as healthy in the Cis + ANA100 group, in which the amount of tGSH was found to be higher. There are studies in the literature which histopathologically demonstrate that hemorrhage areas were developed in the renal tissues of animals treated with cisplatin. ${ }^{21}$

The formation of congested blood vessels due to cisplatin has also been shown in previous studies. ${ }^{22}$ In addition, cisplatin leads to interstitial inflammation and edema in the kidneys. ${ }^{21,23}$ It has been stated that cisplatin causes more severe damage in the kidney tubules, such as necrosis. $^{22}$ The role of free oxygen radicals has also been demonstrated in cellular death due to cisplatin. ${ }^{5}$ 
As a result, severe histopathological damage was developed in the kidney tissue of the cisplatin group, which had high levels of the oxidant MDA and of gene expression, and high amount of pro-inflammatory IL-1 $\beta$, but also had a low amount of the antioxidant tGSH. It was found that the increase in MDA and $I L-1 \beta$ gene expression and amount as well as the decrease in tGSH due to cisplatin in the kidney tissue were significantly inhibited by anakinra at a dose of $100 \mathrm{mg} / \mathrm{kg}$ compared to a dose of $50 \mathrm{mg} / \mathrm{kg}$. It was observed that histopathologically, anakinra at a dose of $100 \mathrm{mg} / \mathrm{kg}$ better protects the renal tissue against the oxidative damage of cisplatin and more efficiently suppresses the production of MDA and IL-1 $\beta$. This information suggests that anakinra may be useful in clinically reducing the toxic effect of cisplatin on the kidneys.

\section{References}

1. Lebwohl D, Canetta R. Clinical development of platinum complexes in cancer therapy: A historical perspective and an update. Eur J Cancer. 1998;34(10):1522-1534.

2. Hartshorn EA, Anand AJ, Bashey B. Newer insights into cisplatin nephrotoxicity. Ann Pharmacother. 1993;27(12):1519-1525.

3. Baek SM, Kwon CH, Kim JH, Woo JS, Jung JS, Kim YK. Differential roles of hydrogen peroxide and hydroxyl radical in cisplatin-induced cell death in renal proximal tubular epithelial cells. J Lab Clin Med. 2003;142(3):178-186.

4. Fouad AA, Morsy MA, Gomaa W. Protective effect of carnosine against cisplatin-induced nephrotoxicity in mice. Environ Toxicol Pharmacol. 2008;25(3):292-297.

5. Özen S, Akyol Ö, Iraz M, et al. Role of caffeic acid phenethyl ester, an active component of propolis, against cisplatin-induced nephrotoxicity in rats. J App/ Toxicol. 2004;24(1):27-35.

6. Zirak MR, Rahimian R, Ghazi-Khansari M, et al. Tropisetron attenuates cisplatin-induced nephrotoxicity in mice. Eur J Pharmacol. 2014;738:222-229.

7. Cvetkovic RS, Keating G. Anakinra. BioDrugs. 2002;16(4):303-311.

8. Hasturk AE, Yilmaz ER, Turkoglu E, et al. Potential neuroprotective effect of Anakinra in spinal cord injury in an in vivo experimental animal model. Neuroscience. 2015;20(2):124.

9. Askin Esen Hasturk M, Yilmaz ER, Turkoglu E, et al. Therapeutic evaluation of interleukin-1 beta antagonist Anakinra against traumatic brain injury in rats. Ulus Travma Acil Cerrahi Derg. 2015;21(1):1-8.
10. Nayki UA, Nayki C, Cetin N, et al. Effect of Kineret ${ }^{\circledR}$ on ovarian ischemia reperfusion injury in a rat model. J Obstet Gynaecol Res. 2016;42(11):1525-1533.

11. Kuyrukluyıldız U, Küpeli I, Bedir Z, et al. The effect of anakinra on paclitaxel-induced peripheral neuropathic pain in rats. Turk J Anaesthesiol Reanim. 2016;44(6):287.

12. Coskun R, Turan MI, Turan IS, Gulapoglu M. The protective effect of thiamine pyrophosphate, but not thiamine, against cardiotoxicity induced with cisplatin in rats. Drug Chem Toxicol. 2014;37(3):290-294.

13. Ohkawa $\mathrm{H}$, Ohishi $\mathrm{N}$, Yagi K. Assay for lipid peroxides in animal tissues by thiobarbituric acid reaction. Anal Biochem. 1979;95(2):351-358.

14. Sedlak J, Lindsay RH. Estimation of total, protein-bound and nonprotein sulfhydryl groups in tissue with Ellman's reagent. Anal Biochem. 1968;25:192-205.

15. Sun Y, Oberley LW, Li Y. A simple method for clinical assay of superoxide dismutase. Clin Chem. 1988;34(3):497-500.

16. Peres $L A B, C$ unha AD Jr. Acute nephrotoxicity of cisplatin: Molecular mechanisms. J Bras Nefrol. 2013;35(4):332-340.

17. Parlakpinar H, Sahna E, Ozer M, Ozugurlu F, Vardi N, Acet A. Physiological and pharmacological concentrations of melatonin protect against cisplatin-induced acute renal injury. J Pineal Res. 2002;33(3):161-166.

18. Girotti AW. Lipid hydroperoxide generation, turnover and effector action in biological systems. J Lipid Res. 1998;39(8):1529-1542.

19. Kilic U, Kilic E, Tuzcu Z, et al. Melatonin suppresses cisplatin-induced nephrotoxicity via activation of Nrf-2/HO-1 pathway. Nutr Metab. 2013;10(1):7.

20. Dinarello CA. Proinflammatory cytokines. Chest. 2000;118(2):503-508.

21. Youssef Nasr A, Al Shahat Ibrahim A. Aged garlic extract ameliorates the oxidative stress, histomorphological and ultrastructural changes of cisplatin-induced nephrotoxicity in adult male rats. Microsc Res Tech. 2015;78(6):452-461.

22. Boroushaki MT, Rajabian A, Farzadnia M, et al. Protective effect of pomegranate seed oil against cisplatin-induced nephrotoxicity in rat. Ren Fail. 2015;37(8):1338-1343.

23. Alfieri AB, Cubeddu LX. Role of NK1 receptors on cisplatin-induced nephrotoxicity in the rat. Naunyn Schmiedebergs Arch Pharmacol. 2000;361(3):334-338.

24. Pabla N, Dong Z. Cisplatin nephrotoxicity: Mechanisms and renoprotective strategies. Kidney Int. 2008;73(9):994-1007.

25. Kisaoglu A, Borekci B, Yapca OE, Bilen H, Suleyman H. Tissue damage and oxidant/antioxidant balance. Eurasian J Med. 2013;45(1):47.

26. Noori S, Mahboob T. Antioxidant effect of carnosine pretreatment on cisplatin-induced renal oxidative stress in rats. Indian J Clin Biochem. 2010;25(1):86-91.

27. Karakoc $\mathrm{H}$, Altintas $\mathrm{R}$, Parlakpinar $\mathrm{H}$, et al. Protective effects of molsidomine against cisplatin-induced nephrotoxicity. Adv Clin Exp Med. 2014;24(4):585-593. 